\title{
Quasi-Real-Time Monitoring of a Citrus Field in Nabeul and Joumine Dam in Tunisia
}

\author{
Ryoichi Doi ${ }^{1}$, Tetsu Ito ${ }^{1}$, Mitsuteru Irie ${ }^{2}$, Jamila Tarhouni ${ }^{3}$, and Masaru Mizoguchi ${ }^{1}$
}

1 Department of Global Agricultural Sciences, Graduate School of Agricultural and Life Sciences, The University of Tokyo, 1-1-1, Yayoi, Bunkyo-ku, Tokyo 113-8657, Japan; ${ }^{2}$ University of Tsukuba North African and Mediterranean Centre for Research and Education, Institut National Agronomique de Tunisie, 43 Av. Charles Nicole, 1082 El Mahrajene Tunis, Tunisia; ${ }^{3}$ Institut National Agronomique de Tunisie, 43 av. Charles Nicole, 1082 El Mahrajene Tunis, Tunisia.

Received: February 28, 2011 / Accepted: January 21, 2013

\begin{abstract}
The management of remote natural resources, e.g., land and water resources, requires frequent visits to these sites which could be costly in time and resources. Telemetry technologies help monitoring, observing and analyzing data at a distance; they use advanced information and communication protocols and have been applied to different applications including agricultural fields. The objective of this study was to evaluate the performance of a new telemetry technology, a field network system, to remotely monitoring natural resources (a citrus grove in the governorate of $\mathrm{Nabeul}$ and the dam of Joumine in the governorate of Bizerte) in Tunisia. The field network system, installed in these two remote locations and powered with solar panels, run well during the test periods. Although the system sent data daily, data transfer stability was a challenge that should be further studied and improved. The manuscript further reports on the quantitative and qualitative performance of the system in Tunisia. Overall, the field network system is a tool that could be used for different applications by researchers, agricultural producers, water resources managers, and policy makers.

Key words: Arid and semi-arid regions; information-and-communication technology; real time monitoring and decision making; wireless communication network.
\end{abstract}

* Corresponding author: aroird@mail.ecc.u-tokyo.ac.jp; roird2000@yahoo.com

\section{Introduction}

Monitoring land and water resources is important for both sustainability and disaster prevention. For example, it is advantageous to know the salinity of water supplies in real-time which enables water managers to take the appropriate remedial measures, e.g., changing the mixture of fresh water resources of different salinity to meet the water quality standards such as the salinity level. Some water resources in Tunisia occasionally do not meet the salinity levels required for their intended use (agricultural, industrial or domestic uses); thus, these water resources are mixed with other water resources with lower salinity levels to dilute the high salinity and help the delivered water that meet the water quality standards. Through daily field monitoring of apples in Aomori, Japan, Kish et al. (2010) found a relationship between the time of harvest visually determined by experienced farmers and the apple color as described by the red-green-blue color description model (Doi et al. 2010). According to these authors (Kish et al, 2010), the best harvest time was objectively determined through real-time remote monitoring of apple colors.

Combining the latest data acquisition and distribution technologies (Lewis 2004) may enable us to remotely monitor what is happening at agricultural production sites (Vellidis et al., 2007; Wang et al., 2006) and water resources (Kashef et al., 2006). This concept of minimizing the time lag before taking optimal actions and maximizing the quantitative accuracy was well established early this century (Berger et al., 2002). Nevertheless, there are only a limited number of case studies on the effectiveness of this technology in areas of agricultural pro- 
duction and water resources management. The main reasons for this delay in using these technologies are i) the power requirements of the computing devices for these technologies, and ii) the dependence on direct cable connection to transfer large data packets (Fukatsu and Nanseki 2009).

We developed a new telemetry system (an information and communication system), hereafter called the "field network system," that overcomes these two major limitations and is used for monitoring remote sites. The field network system can send daily (or sub-daily) data from the field to any place that is covered by mobile phone or Internet services. The basic module of the system consists of a computer, a data logger, and a mobile phone. This system can log and transfer data for water level, water and soil electrical conductivity, air temperature, wind speed, wind direction, optical image, humidity, precipitation, soil moisture, soil temperature, and solar radiation. The objective of this study was to evaluate the performance of a new telemetry technology, a field network system, to remotely monitoring land and water resources (a citrus grove in the governorate of Nabeul and the dam of Joumine in the governorate of Bizerte) in Tunisia.

\section{Materials and Methods}

\subsection{Research Sites}

The field network system was installed in two sites; the first site is a citrus grove near the city of Nabeul ( $\left.36^{\circ} 59^{\prime} \mathrm{N}, 9^{\circ} 36^{\prime} \mathrm{E}\right)$, the governorate of $\mathrm{Nabeul}$, and the second site is Joumine dam $\left(36^{\circ}\right.$ $59^{\prime} \mathrm{N}, 9^{\circ} 36^{\prime} \mathrm{E}$ ) in the governorate of Bizerte. Both sites started operating during the month of September 2010. Mean annual precipitations are $400 \mathrm{~mm}$ (Nabeul) and $550 \mathrm{~mm}$ (at Mateur, $7 \mathrm{~km}$ from Joumine dam), and mean annual temperatures are $19^{\circ} \mathrm{C}$ (Nabeul) and $18^{\circ} \mathrm{C}$ (Mateur). The citrus grove is part of an experimental site related to a reclaimed water project that was established in the late 1980's (Mahjoub et al. 2009), while Joumine dam was completed in 1983. Data were acquired over a 48-day period (September 14 - October 312010 for the citrus grove) and over 18-day period (September 15 - October 22010 for Joumine dam). In the citrus grove site, additional optical images were obtained on November 27, December 13 2010, and February 152011.

\subsection{The field Network System}

The field network system was developed by $\mathrm{X}$ Ability Co., Ltd., Tokyo, Japan (Mizoguchi et al., 2010a). The basic module consisted of a small PC (Linux box), a data logger, and a mobile phone that were connected to a small camera (Mizoguchi et al., 2010b). At Joumine dam, a Davis weather station (Davis Instruments Corp., California, USA) was wirelessly connected to the basic module. The weather station collected air temperature and solar radiation data. The computer was configured to send collected dataset every 24 hours through the Tunisian Telecom mobile phone service to an Internet server. The system operated for 30 minutes every day to minimize power consumption. An optical image of each site was captured at 12.05 from the citrus grove and at 13.10 from Joumine dam every day and was sent over the mobile phone service to an Internet server. Electricity at each site was supplied by a compact $6 \mathrm{~W}-0.35 \mathrm{~A}$ solar panel (Figure 1).

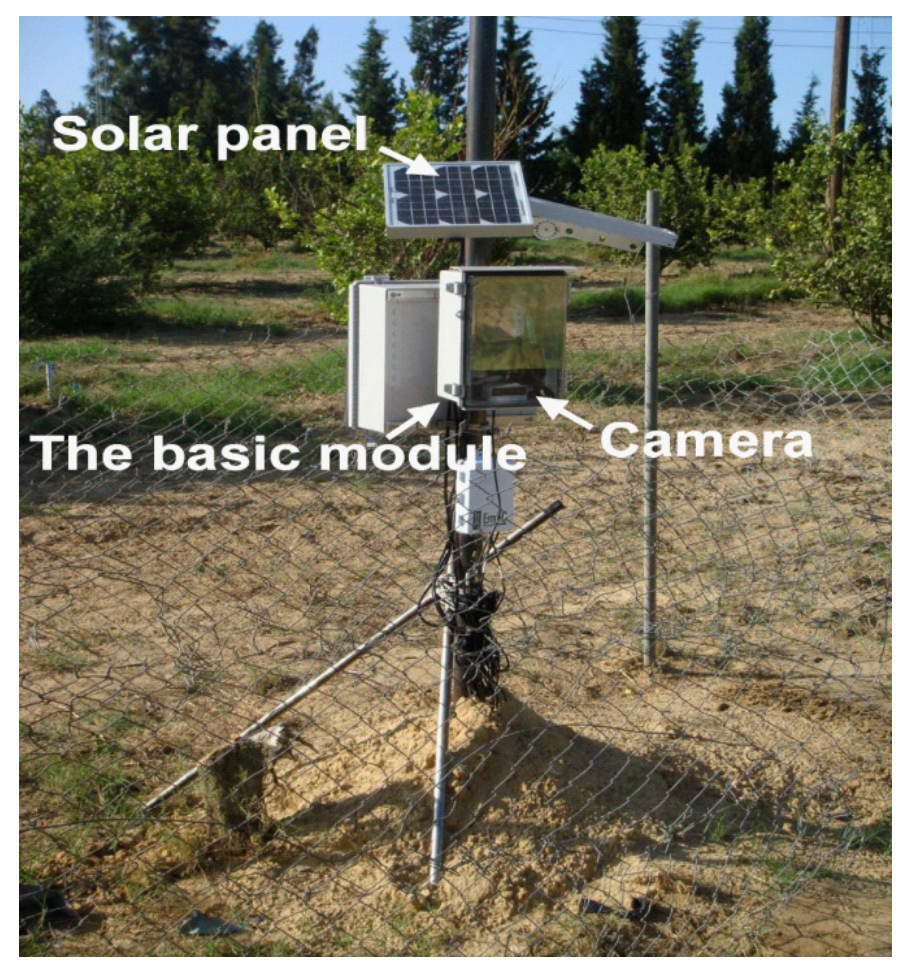

Figure 1. The basic module part of the field network system at a citrus grove near the city of Nabeul, the governorate of Nabeul, Tunisia 


\section{Results and Discussion}

At Joumine dam site, images were collected daily. The images show the weather conditions of the site at the times the photographs were taken (Figure 2). On September 24 2010, the weather was cloudy, and the temperature dropped compared to the previous day. The photographs can show changes of the water level in the dam. The photograph of October 1 shows a decrease of the water level in the dam. As a result, more rocks are shown than during the photographs of September. Greater changes in the water level could have been seen if the observational period included the dry summer and wet winter periods.

There were days when we didn't have photographs because of unsuccessful data transfers. At the dam site, we downloaded images on ten occasions: nine in September (15, 19 - 22, 24, 26, 27 , and 30 ) and one on October 1 during the monitoring period following the installation of the field network system. There were some computer software glitches such that the personal computer sometimes did not recognize the camera. Another possible explanation for the unsuccessful image data transfers could be some limitation of the mobile phone network in the area. This network could have been too busy to properly transfer the data information. Another possible cause could be the size of the images being transferred (each image was around 14,000 bytes). Image data transfers may have taken longer than that required for temperature and solar radiation data, allowing for interruptions during data transfers, as indicated on Oct. 25 in Figure 3. These possible causes of unsuccessful data transfers will be investigated in order to make future data transfers successful. In monitoring land and water resources, the field network sys- tem can integrate additional variables, e.g., soil moisture, soil temperature, and electrical conductivity of water and soil. For example, remotely monitoring the salinity of water resources enables water resource managers to determine the optimum ratio of dilution supported by the quasi-real-time data. An electrical conductivity probe can be connected to the basic module, which enables the monitoring of the electrical conductivity at an offsite location. Water level can also be monitored by adding a water pressure sensor to the basic module. The system established for this study is cost-effective and versatile because the basic parts were assembled by our research team though the aforementioned errors remain to be further investigated.

In the citrus grove near the city of Nabeul, the monitoring was relatively more successful than that at the dam site (Figure 3 ). Within a month following the installation of the field network system, the system successfully transferred 23 images for 23 days. This is relatively a more successful data transfer; it demonstrates that the failure of the PC to recognize the camera cannot be the sole cause of the failure of the data transfer from the dam site. The location of the citrus grove is more favorable for data transfer than the dam site because this area has much better mobile phone network coverage due to the booming economic activities of the region such as tourism in the region of Hammamet. We targeted a single citrus tree to monitor changes in fruit size and color as a function of time (Figure 4). If we set color invariants as the color standards, the fruit growth and changes in fruit color will be quantitatively measured by analyzing the images, as in the case study conducted by Kato et al. (2012); their research found that the best time for apple harvest in Aomori prefecture, Japan could be objectively determined by profiling the fruit

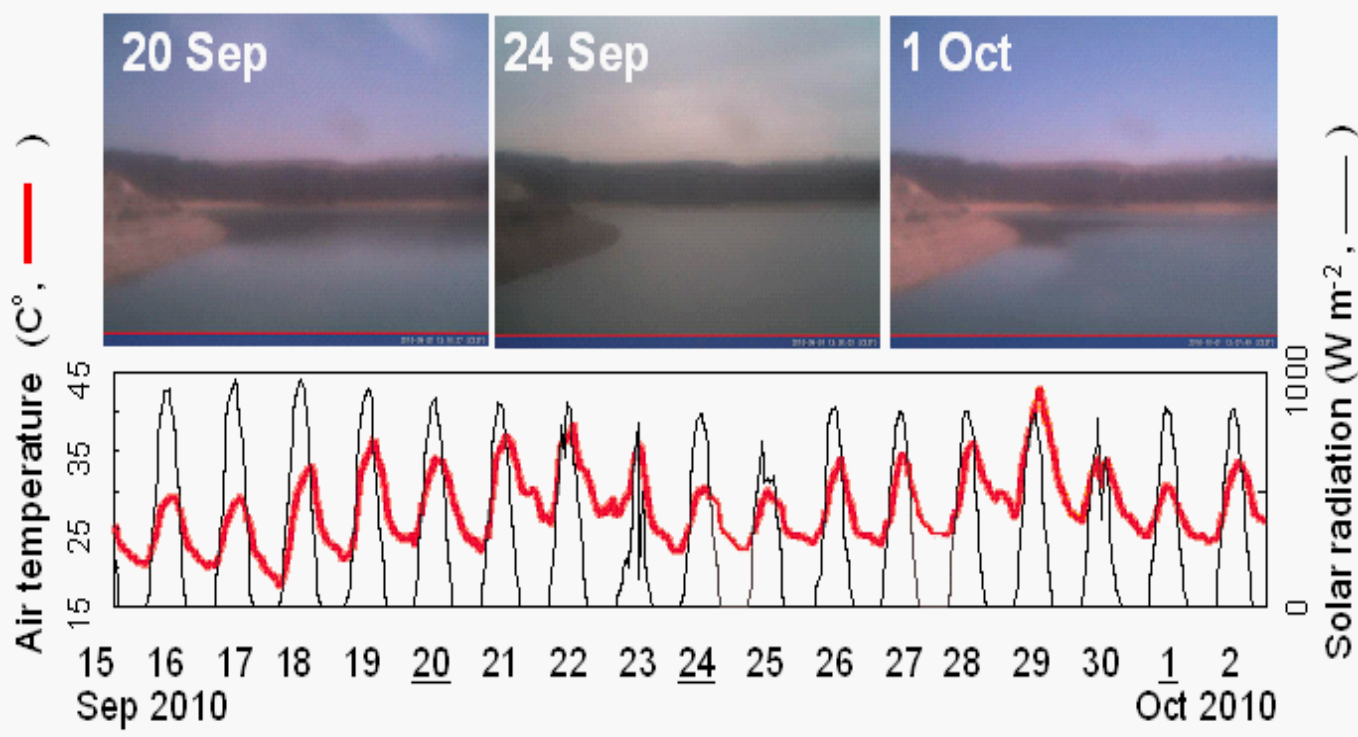

Figure 2. Changes in captured images, air temperature, and solar radiation at a citrus grove near the city of Nabeul, the governorate of Nabeul. The images were of the underlined days. 


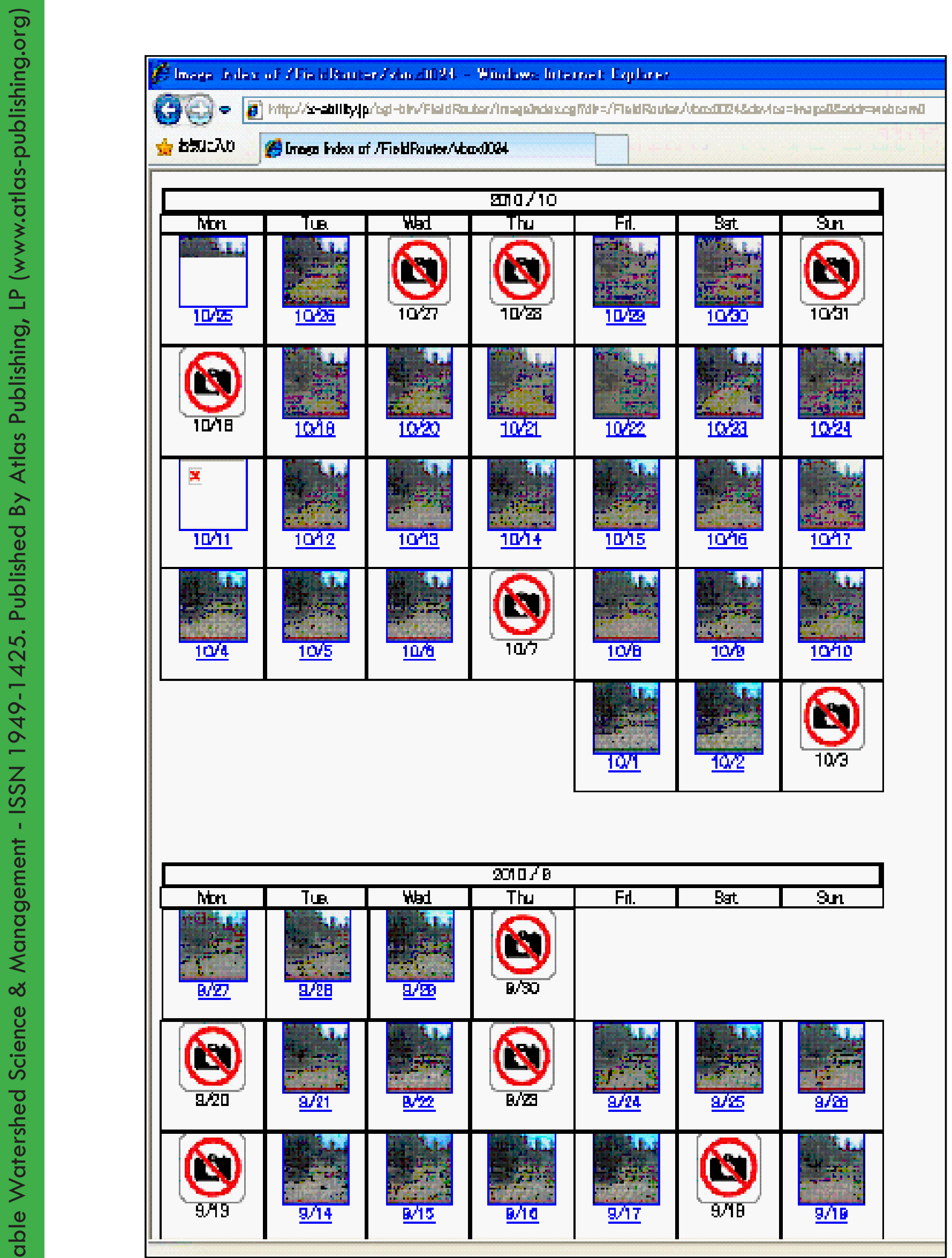

Figure 3. Daily-captured images of a citrus tree in the experimental field in Tunisia. The images were transferred to a server so as to be available through the Internet. 


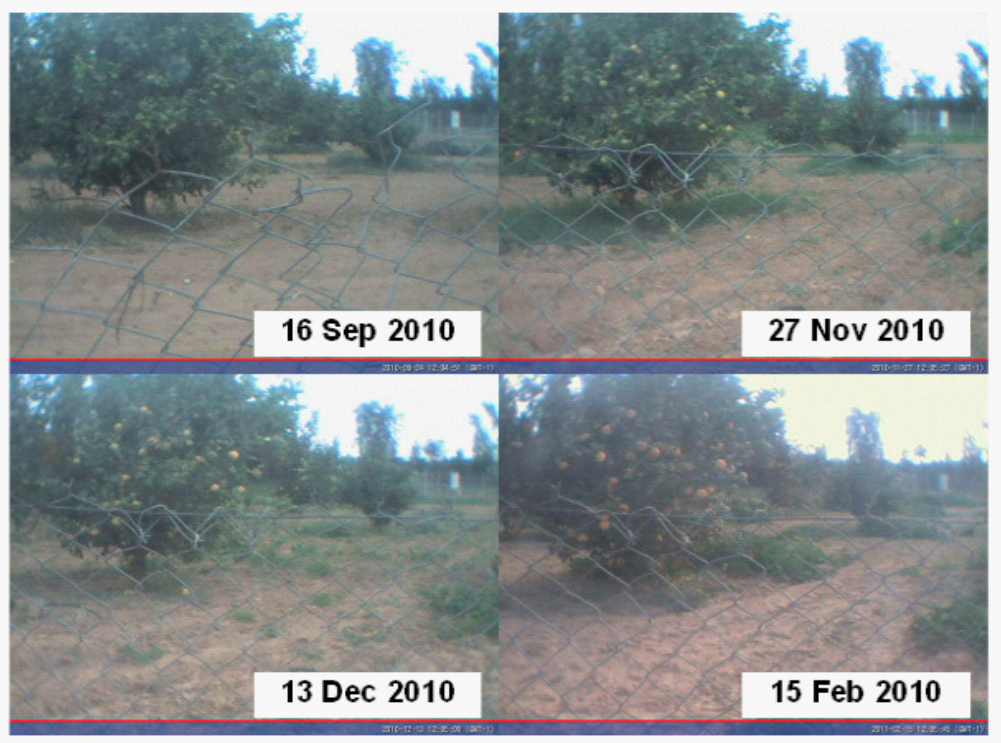

Figure 4. Changes in color and size of citrus fruits shown in consecutively captured images.

color based on a color model (Doi et al., 2010). As in the case of the apple, using color invariants, it is expected that a relationship could be established between changes in citrus fruit quality and environmental factors such as air temperature (Doi, 2012). As in Aomori, Japan, it seems that this telemetry technology, the real-time monitoring of land and water resources, can be applied in Tunisia to meet some of this country's local needs. In Aomori, the experienced farmers asked for the aforementioned new application of the field network system when transferring their knowledge to younger people. As in this case, new applications may result from communication with farmers as well as land and water resource managers. For this reason, we would like to introduce the field network system to those who are facing issues and/or needs in land and water resources management.

\section{Conclusions}

This study enabled us to evaluate a new telemetry technology and to identify the technical problems that must be solved before the advantages of the field network system can be fully utilized. Nevertheless, supported by wireless communication and low power consumption, the field network system can automatically send acquired data from rural areas if there is reliable mobile phone service coverage in the area. Therefore, developing, improving, and technically extending the field network system is valuable in terms of regional and socioeconomic development (Adinarayana et al., 2008).

\section{Acknowledgements}

We thank the Data Integration and Analysis System project of the Japan Agency for Marine-Earth Science and Technology for financial support. We are also grateful to Mr. Hammadi Ali and
Mr. Ben Khelil, the citrus field managers, Mr. Chagoulmi Churif, manager of the Joumine dam, as well as all of the staff members of these sites for their continuous support.

\section{References}

Adinarayana J, S Azmi, G Tewari, and D.Sudharsan (2008) GramyaVikas: A distribute collaboration model for rural development planning. Computers and Electronics in Agriculture 62 (2): 128-140.

Berger D. RD Hansen, and A Hilton (2002) Using the world-wide-web as a support system to enhance water management. In: Proc. FAOICD workshop, Irrigation Advisory Services and Participatory Extension in Irrigation Management, Jul 24 2002, Montreal, Canada

Doi R, C Wachrinrat, S Teejuntuk, K Sakurai, and P Sahunalu (2010) Semiquantitative color profiling of soils over a land degradation gradient in Sakaerat, Thailand. Environmental Monitoring and Assessment 170 (1-4): 301-309.

Doi R. (2012) Simple luminosity normalization of greenness, yellowness and redness/greenness for comparison of leaf spectral profiles in multi-temporally acquired remote sensing images. Journal of Biosciences 37 (4): 723-730.

Fukatsu T, and T Nanseki (2009) Monitoring system for farming operations with wearable devices utilized sensor networks. Sensors 9 (8): $6171-6184$

Kashef O, L Morton, and B Miller (2006) Using technology to develop integrated water resources management schemes. Proc: ASABE Annual Meeting. July 9-12, 2006.Portland, Oregon. 15 pp.

Kato K, T Kishi, E Sato, and M Mizoguchi M (2012) Inheritance of apple cultivation technique by field monitoring with farmers participation. Water, Land and Environmental Engineering 80 (9): 7-11.

Kishi T, K Kato, E Sato, and M Mizoguchi (2010) Development of indicator for apple production using simple monitoring system. Proc: Annual meeting of the Japanese Society of Irrigation. Drainage and Rural Engineering. Aug 31-Sep 2, 2010, Kobe, Japan. in CD, 2 pp. Lewis FL (2004) Wireless Sensor Networks. In: DJ Cook, SK Das (eds.) Smart environments: technologies, protocols, and applications. John 
Wiley \& Sons, Inc., pp. 13-46.

Mahjoub O, M Leclercq, M Bachelot, C Casellas, A Escande, P Balaguer, A Bahri, E Gomez, and H Fenet (2009) Estrogen, aryl hydrocarbon and pregnane $X$ receptors activities in reclaimed water and irrigated soils in Oued Souhil area (Nabeul, Tunisia). Desalination 246 (1-3) 425-34.

Mizoguchi M, T Ito, and S Mistuishi (2010a) Ubiquitous monitoring of agricultural fields in Asia using sensor network. Proc: 19th World Congress of Soil Science. pp 125-128. Aug 1-6, 2010. Brisbane, Australia

Mizoguchi M, T Ito, and S Mistuishi (2010b) Field network system for soil sensing in remote agricultural fields. Proc: 49th Japanese Soil Physic
Annual Meeting. Oct 23-24, 2010. Tottori, Japan. 2pp.

Lewis FL (2004) Wireless Sensor Networks. In: DJ Cook, SK Das (eds.) Smart environments: technologies, protocols, and applications. John Wiley \& Sons, Inc., pp. 13-46.

Vellidis G, V Garrick, S Pocknee, C Perry, C Kvien, and M Tucker (2007). How wireless will change agriculture. In: JV Stafford (ed.) Precision Agriculture '07 - Proceedings of the Sixth European Conference on Precision Agriculture (6ECPA), Skiathos, Greece, pp. 57-67.

Wang N, N Zhang, and M Wang (2006) Wireless sensors in agriculture and food industry-Recent development and future perspective. Computers and Electronics in Agriculture 50 (1): 1-14. 